\title{
ASSESSMENT OF PATTERN AND OUTCOME OF TRAUMATIC HEAD INJURIES IN MENOUFIA UNIVERSITY HOSPITAL OVER ONE YEAR
}

\author{
Reham Hassan El- Farouny \\ Forensic Medicine and Clinical Toxicology Department, Faculty of Medicine- \\ Menoufia University, Egypt. \\ Corresponding author: Reham Hassan El- Farouny. E-mail address:dr_reham2004@yahoo.com.
}

Submit Date 30-06-2020

Revise Date 09-08-2020

Accept Date 2020-08-19

\begin{abstract}
Introduction: Head injuries (HI) are major threat to public health; they are significant risk factors for mortality in all age groups of population around the world. Head injury has impacted the countries ' economies causing some financial losses, and reduced productivity. Objectives: The purpose of this study was to assess pattern, occurrence mode, severity, associated factors, and outcome of traumatic head injuries in Menoufia University Hospital. Methodology: This was a cross sectional prospective study of 423 cases of traumatic head injury (THI) attended to Menoufia University Hospital over one year from 1st of January 2019 to the end of December 2019. Data about patient demographics, cause of injury, the instruments used, site, type of skull fractures or hemorrhage if present were gathered. Head injury severity was assessed by using the Glasgow Coma Scale (GCS) and outcome at time of discharge was documented. Results: Total 423 cases of traumatic head injury that met the inclusion criteria. $31 \%$ were in age between $(30-<45 y),(25 \%)$ in age from $(15-<30 y)$. Males approximately were three times more than females. Cases from rural areas represented $(59.6 \%)$ versus $(40.4 \%)$ from urban areas. Laborer followed by student were the mostly affected categories $(49.5 \%)$. The commonest cause was road traffic accidents (RTA) in 50.8\%. Blunt instrument was frequently used agent $(91 \%)$, while the most frequent site affected in skull was the more than one site in $(30.3 \%)$. Skull fracture was the most common finding in computed tomography (CT) $(31.7 \%)$. According to GCS, Mild cases (13-15) predominant than other degrees of coma representing $84.4 \%$. The most common outcome was complete recovery $(89.6 \%)$. highly significant relation was found between outcome and GCS. Conclusion: Traumatic injury to the head is a common injury among emergency unites' cases. The total number of cases was 423 . The majority of cases were males. The age group most affected was between $(30-<45 y)$. Rural cases outnumbered those from urban areas. The most affected categories were laborer and student. RTA was the most common cause of traumatic head followed by assault. Intracranial hemorrhage and skull fractures are common association with THI.
\end{abstract}

Key words: traumatic, head injuries, pattern, traffic accident, Menoufia.

\section{INTRODUCTION}

Head injuries (HI) are major threat to public health; they are significant risk factors for mortality in all age groups of population around the world (Wang et al., 2018). Traumatic injuries are predicted to be among the top twenty leading causes of deaths worldwide by 2030 (Mahran et al., 2013).
Any injury that results in damage to scalp, skull or brain can be considered as an HI that can be caused by traffic accidents, falls, sports or wounds from firearms. Vehicle accidents are one of the most prevalent causes of traumatic head injury (THI); they are considered one of the major causes of road traffic accidents (RTA) fatality (Rupani et al., 2013). 
Head injuries severity ranged from mild, moderate to severe as it could cause changes in cell structure and function, and/or tissue damage, such as contusion, hemorrhage, and diffuse axonal injury (Pearn et al., 2017). Skull fracture and hemorrhage are common association, which may be present with head trauma and affect the outcome of the case (Ranjit et al., 2011 and Meaney\& Smith, 2011).

HI account for almost $50 \%$ of all injuries and it is now one of the biggest problems faced by almost 57 million people globally living with a neurological condition caused by traumatic head injury (THI), with 10 million of them in need for long medical treatment. The median prevalence of traumatic brain injury in the United States was 73.5/100,000 (Alnaami et al., 2019). The incident rate is high in Latin America and Sub-Saharan Africa; 150-170 per 100,000 compared with a global average of 106 per 100,000 due to road traffic accidents. Troubled cognition is the characteristic symptom of head injury that can trigger memory, concentration, learning and balance difficulties; but the injury can also affect behavior, emotion and motor control (Walle et al., 2018).

Head injury has impacted the countries' economies causing some financial losses, and reduced productivity. In 2000, nearly US\$ 60 billion was used to solve head injuries sequels. A study based in the US revealed that most frequent injury among young children was head injuries (Mostafa et al, 2016; Alnaami et al., 2019).

In spite that the Egyptian injuries are many times larger than documented as a result of underreporting and misdiagnosis; injury in Egypt is a considerable burden as it was the fifth leading cause of death in 2004 (Mahran et al.,2013; Abdelgeleel et al., 2019).

Trauma in Egypt is a serious health issue which requires priority attention. Policy making to improve community understanding and preparation for the preventive and curative trauma program in addition to setting up a trauma network is critical for reducing the impact of injuries (Mahran et al., 2016).

The aim of this study was to assess the incidence, pattern, mode of occurrence, severity, associated factors and the outcome of traumatic head injuries in Menoufia University Hospital.

\section{SUBJECTS AND METHODS}

This was a cross sectional prospective study conducted on 423 cases of traumatic head injury attended to Menoufia University Hospital and had a primary medicolegal report during the period from 1st of January 2019 to the end of December 2019.

Approval from the Ethical Committee of Faculty of Medicine, Menoufia University was taken. A primary medicolegal report and valid consent was constructed and fulfilled for every case.

Exclusion criteria were those cases who refuse to sign the consent, cases discharged previous to complete assessment to their clinical status upon their request, or readmitted to hospital for treatment of complication or rehabilitation.

Data about patient sociodemographics, mechanism of injury, the instruments used, site and type of skull fractures or hemorrhage if present according to the result of radiological scanning were gathered. Head injury severity was assessed by using the Glasgow Coma Scale (GCS). The GCS relay on the function of the central nervous system (CNS) which consists of verbal, motor, and eye-opening responses. The score was either mild (score $=13-15)$, moderate $($ score $=9-12)$ or severe (score <9) (Salottolo et al., 2014). Also, outcome of these cases at the time of discharge from hospital was assessed either recovered, discharged against medical advice, dead or occurrence of permanent infirmity.

The collected data were tabulated and analyzed statistically using a personal computer with a Statistical Package of Social Science (SPSS) Version 20 and the appropriate statistics were used; number and percentage used as descriptive statistics 
and analytic statistics by chi square test $(\chi 2$ test). The $\mathrm{P}$ value above 0.05 was considered statistically insignificant. $\mathrm{P}$ value below 0.05 was considered statistically significant. P value considered statistically highly significant if less than or equal 0.001 (Dawson and Trapp, 2004).

\section{RESULTS}

This was a cross sectional, prospective study conducted over one-year from 1st of January 2019 to the end of December 2019. Total 423 cases of traumatic head injury attended to Menoufia University Hospital emergency unite.

The highest percent of them $(31 \%)$ were in age group between $(30-<45 y)$ followed by $(25 \%)$ in age from $(15-<30 y)$ and the least cases were among age group more than 60 years by $5 \%$ of all cases. Males approximately were three times more than females as they represent $74 \%$ of the studied sample. Cases from rural areas represented $(59.6 \%)$, while $40.4 \%$ were from urban areas. Laborer followed by student were the mostly affected categories $(49.5 \%)$ while the least affected was the below school age group (4.73\%). Most of cases $(54.37 \%)$ were single in spite of $(39.01 \%)$ of them were married and $(6.6 \%)$ were widow as seen in table (1).

The most common cause of traumatic head injury was due to road traffic accidents (RTA) in $50.8 \%$ followed by assault $(38.1 \%)$ and lastly due to fall $(11.1 \%)$. Blunt instrument causing head trauma was the most frequent blamed instrument in (91\%) versus $(6.6 \%)$ caused by sharp instrument. Moreover, the most frequent site affected was the more than one sites in $(30.3 \%)$ while base of skull were the least frequent sites $(2.6 \%)$.

Scalp injury was present mostly in all cases as $49.9 \%$ complained mixed injuries in the form of (contusion, contused wound, and/ or cut wound), $26 \%$ had abraded contusion and $19.4 \%$ of cases had contused wound versus $4.7 \%$ of cases had cut wound.

As regard the severity of injured cases according to GCS; mild cases outnumbered the other degrees representing (84.4\%) then moderate and sever degree. Complete recovery was the most prevalent outcome representing $(89.6 \%)$, followed by cases whom discharged against medical advice and death by (5.2\%) and (4\%) respectively, while the least number of patients had permanent infirmity in the form of bone loss after surgical intervention by $(1.2 \%)$ as seen in table (2).

According to CT finding in traumatic head injury cases; skull fracture was the most common finding $(31.7 \%)$ of all cases followed by intracranial hemorrhage (25.5 $\%)$ then mixed finding in $(20.3 \%)$, free finding constituted $(15.8 \% \%)$ as they were with no apparent lesion in CT or not indicated for doing it, while the least common were brain contusion without finding (6.6\%) as shown in table (3).

On the other hand, fig (1) declared the distribution of cases in fracture where the highest percept among fractures cases were simple fracture in $39.5 \%$, followed by depressed fracture in $31.3 \%$, comminuted fracture $10.4 \%$ and fracture base in $9.7 \%$, and lastly mixed types of fracture in $8.9 \%$.

According to distribution of cases in hemorrhage the highest percent of hemorrhage cases were $\mathrm{EDH}$ in $(55.5 \%)$, followed by $\mathrm{SAH}$ in $(19.4 \%), \mathrm{SDH}$ in $(12.9 \%)$ and lastly ICH and mixed types of hemorrhage in (6.4\%) and (5.5\%) respectively as seen in fig (2).

Highly statistically significant difference was found between different causes of traumatic head injury in relation to the age groups where RTA was more common among age group $(45-<60 y)$ by $(27.4 \%)$, fall was more common in age group less than 15 y by $34 \%$, while assault injuries were more common among age group (30- <45y) by (39.8\%) (X $2=44.89$ and $\mathrm{P}$ value $<0.001)$ table (4).

Table (5) showing that $(32.6 \%)$ of traumatic head injury due to RTA were affecting multiple sites of the skull bone, while the highest percent $28.6 \%$ of assault cases were in the frontal region and $36.2 \%$ of fall cases were affecting the parietal area; 
and this was statistically significant as $\left(\mathrm{X}^{2}\right.$ $=23.046$ and $\mathrm{P}$ value <0.01).

The relation between outcome of traumatic head injury and severity of cases in form of GCS was highly statistically significant as $89.2 \%$ of recovered cases were mild in severity, while $52.9 \%$ and $35.3 \%$ of dead cases were sever and moderate score GCS respectively as shown in fig (3).
Table (6) shows significant relation between the radiological finding in CT and the outcome of cases where the highest percent of recovered cases $(29.6 \%)$ had simple fissure fracture, while $41.2 \%$ of dead cases had mixed radiological finding (fracture, brain contusion, hemorrhage). On the other side $80 \%$ of cases with Permanent infirmity in form of (Bone Loss) had skull fracture.

Table (1): Socio-demographic characteristics of the studied traumatic head injury cases.

\begin{tabular}{|c|c|c|c|}
\hline \multicolumn{2}{|c|}{ Value } & No. & $\%$ \\
\hline \multirow{5}{*}{ Age } & $<15 y$ & 72 & $17.0 \%$ \\
\hline & $15-<30 y$ & 106 & $25.1 \%$ \\
\hline & $30-<45 y$ & 131 & $31.0 \%$ \\
\hline & $45-<60 y$ & 93 & $22.0 \%$ \\
\hline & $\geq 60 y$ & 21 & $5.0 \%$ \\
\hline \multirow[t]{2}{*}{ Sex } & Male & 313 & $74.0 \%$ \\
\hline & Female & 110 & $26.0 \%$ \\
\hline \multirow[t]{2}{*}{ Residence } & Rural & 252 & $59.6 \%$ \\
\hline & Urban & 171 & $40.4 \%$ \\
\hline \multirow{7}{*}{ Occupation } & Below school age & 20 & $4.73 \%$ \\
\hline & Employee & 39 & $9.22 \%$ \\
\hline & House wife & 45 & $10.64 \%$ \\
\hline & Not working & 73 & $17.26 \%$ \\
\hline & Student & 95 & $22.46 \%$ \\
\hline & Laborer & 115 & $27.19 \%$ \\
\hline & Professional & 36 & $8.51 \%$ \\
\hline \multirow[t]{3}{*}{ Marital status } & Married & 165 & $39.01 \%$ \\
\hline & Single & 230 & $54.37 \%$ \\
\hline & widow & 28 & $6.6 \%$ \\
\hline \multicolumn{2}{|c|}{ Total } & 423 & $100.0 \%$ \\
\hline
\end{tabular}

Table (2): Details about cause of injury, type of the instrument, site of skull bone affected, severity of trauma (GCS), type of scalp injury and outcome among traumatic head injury cases.

\begin{tabular}{|l|c|c|c|}
\hline \multirow{4}{*}{ Vause of injury } & No. & $\%$ \\
\hline & Road Traffic Accident (RTA) & 215 & $50.8 \%$ \\
\cline { 2 - 4 } & Assault & 161 & $38.1 \%$ \\
\cline { 2 - 4 } & Fall & 47 & $11.1 \%$ \\
\hline Type of instrument used & Blunt & 385 & $91 \%$ \\
\cline { 2 - 4 } & Sharp & 28 & $6.6 \%$ \\
\cline { 2 - 4 } & Blunt and sharp & 10 & $2.4 \%$ \\
\hline \multirow{4}{*}{ Site of skull injury } & Frontal & 87 & $20.6 \%$ \\
\cline { 2 - 4 } & Occipital & 41 & $9.7 \%$ \\
\cline { 2 - 4 } & Partial & 111 & $26.2 \%$ \\
\cline { 2 - 4 } & Temporal & 45 & $10.6 \%$ \\
\cline { 2 - 4 } & Fracture base & 11 & $2.6 \%$ \\
\hline
\end{tabular}




\begin{tabular}{|l|c|c|c|}
\hline & More than one sites & 128 & $30.3 \%$ \\
\hline \multirow{4}{*}{ Scalp injury } & Abraded contusion & 110 & $26 \%$ \\
\cline { 2 - 4 } & Contused Wound & 82 & $19.4 \%$ \\
\cline { 2 - 4 } & Cut Wound & 20 & $4.7 \%$ \\
\cline { 2 - 4 } & Mixed injuries & 211 & $49.9 \%$ \\
\hline \multirow{3}{*}{ Glasgow Coma score (GCS) } & Mild (13-15) & 357 & $84.4 \%$ \\
\cline { 2 - 4 } & Moderate (9-12) & 46 & $10.9 \%$ \\
\cline { 2 - 4 } & Sever (3-8) & 20 & $4.7 \%$ \\
\cline { 2 - 4 } & Recovered & 379 & $89.6 \%$ \\
\cline { 2 - 4 } & Discharge against medical advice & 22 & $5.2 \%$ \\
\cline { 2 - 4 } & Death & 17 & $4 \%$ \\
\cline { 2 - 4 } & Permanent infirmity & 5 & $1.2 \%$ \\
\hline Total & Bone Loss) & 423 & $100.0 \%$ \\
\hline
\end{tabular}

Table (3): Results of computed tomography (CT) scan findings among traumatic head injury cases.

\begin{tabular}{|c|c|c|c|c|}
\hline $\begin{array}{l}\text { Radiological } \\
\text { finding }\end{array}$ & NO $(\%)$ & TYPE & NO & $\%$ \\
\hline Brain contusion & $28(6.6 \%)$ & Brain contusion & 28 & $6.62 \%$ \\
\hline \multirow{5}{*}{ Fracture } & \multirow{5}{*}{$134(31.7 \%)$} & Simple fissure & 53 & $12.53 \%$ \\
\hline & & Depressed & 42 & $9.93 \%$ \\
\hline & & Depressed comminuted & 14 & $3.31 \%$ \\
\hline & & Fracture base & 13 & $3.07 \%$ \\
\hline & & Combined types of fractures & 12 & $2.84 \%$ \\
\hline \multirow{5}{*}{ Hemorrhage } & \multirow{5}{*}{$108(25.5 \%)$} & $\begin{array}{l}\text { Extra Dural Hemorrhage } \\
(\mathrm{EDH})\end{array}$ & 60 & $14.18 \%$ \\
\hline & & $\begin{array}{l}\text { Subarachnoid Hemorrhage } \\
\text { (SAH) }\end{array}$ & 21 & $4.96 \%$ \\
\hline & & $\begin{array}{l}\text { Subdural Hemorrhage } \\
\text { (SDH) }\end{array}$ & 14 & $3.31 \%$ \\
\hline & & $\begin{array}{l}\text { Intracerebral hemorrhage } \\
\text { (ICH) }\end{array}$ & 7 & $1.65 \%$ \\
\hline & & $\begin{array}{c}\text { Combined types of } \\
\text { hemorrhages }\end{array}$ & 6 & $1.42 \%$ \\
\hline Mixed finding & $86(20.3 \%)$ & $\begin{array}{c}\text { (fracture, brain contusion, } \\
\text { hemorrhage) }\end{array}$ & 86 & $20.3 \%$ \\
\hline \multirow[t]{2}{*}{ Free (No lesion) } & $67(15.8 \%)$ & Free & 67 & $15.8 \%$ \\
\hline & & Total & 423 & $100.0 \%$ \\
\hline
\end{tabular}


Table (4): Chi square statistical analysis of the relation between cause of trauma and age.

\begin{tabular}{|c|c|c|c|c|c|c|c|c|c|c|}
\hline \multirow{3}{*}{ Age } & \multicolumn{8}{|c|}{ Cause of trauma } & \multirow{3}{*}{$\mathbf{X}^{2}$} & \multirow{3}{*}{$\mathbf{P} * *$} \\
\hline & \multicolumn{2}{|c|}{ RTA } & \multicolumn{2}{|c|}{ Assault } & \multicolumn{2}{|c|}{ Fall } & \multicolumn{2}{|c|}{ Total } & & \\
\hline & No. & $\%$ & No. & $\%$ & No. & $\%$ & No. & $\%$ & & \\
\hline$<15 y$ & 37 & 17.2 & 19 & 11.8 & 16 & 34 & 72 & 17 & \multirow{6}{*}{44.89} & \multirow{6}{*}{0.000} \\
\hline $15-<30 y$ & 48 & 22.3 & 54 & 33.5 & 4 & 8.5 & 106 & 25.1 & & \\
\hline $30-<45 y$ & 54 & 25.1 & 64 & 39.8 & 13 & 27.7 & 131 & 31 & & \\
\hline $45-<60 y$ & 59 & 27.4 & 23 & 14.3 & 11 & 23.4 & 93 & 22 & & \\
\hline$\geq 60 y$ & 17 & 7.9 & 1 & 0.6 & 3 & 6.4 & 21 & 5 & & \\
\hline Total & 215 & 100 & 161 & 100 & 47 & 100 & 423 & 100 & & \\
\hline
\end{tabular}

$* * \mathrm{P} \leq 0.001$ is highly significant (HS)

Table (5): Chi square statistical analysis of the relation between cause of trauma and affected site of the skull bone.

\begin{tabular}{|c|c|c|c|c|c|c|c|c|c|c|}
\hline \multirow{3}{*}{ Site } & \multicolumn{6}{|c|}{ Cause of trauma } & \multirow{2}{*}{\multicolumn{2}{|c|}{ Total }} & \multirow{3}{*}{$X^{2}$} & \multirow{3}{*}{$\mathbf{P}^{* *}$} \\
\hline & \multicolumn{2}{|c|}{ RTA } & \multicolumn{2}{|c|}{ Assault } & \multicolumn{2}{|c|}{ Fall } & & & & \\
\hline & No. & $\%$ & No. & $\%$ & No. & $\%$ & No. & $\%$ & & \\
\hline Frontal & 34 & 15.8 & 46 & 28.6 & 7 & 14.9 & 87 & 20.6 & & \\
\hline Occipital & 19 & 8.8 & 21 & 13 & 1 & 2.1 & 41 & 9.7 & & \\
\hline Parietal & 66 & 30.7 & 28 & 17.4 & 17 & 36.2 & 111 & 26.2 & & \\
\hline Temporal & 20 & 9.3 & 19 & 11.8 & 6 & 12.8 & 45 & 10.6 & 23.046 & 0.011 \\
\hline Fracture base & 6 & 2.8 & 4 & 2.5 & 1 & 2.1 & 11 & 2.6 & & \\
\hline Multiple sites & 70 & 32.6 & 43 & 26.7 & 15 & 31.9 & 128 & 30.3 & & \\
\hline Total & 215 & 100 & 161 & 100 & 47 & 100 & 423 & 100 & & \\
\hline
\end{tabular}

$* * \mathrm{P} \leq 0.001$ is highly significant (HS).

Table (6): Chi square statistical analysis of the relation between the outcome and radiological finding.

\begin{tabular}{|c|c|c|c|c|c|c|c|c|c|c|c|c|}
\hline \multirow{3}{*}{$\begin{array}{l}\text { Radiological } \\
\text { finding }\end{array}$} & \multicolumn{8}{|c|}{ Outcome } & & & \multirow{3}{*}{$\mathrm{X} 2$} & \multirow{3}{*}{ P* } \\
\hline & \multicolumn{2}{|c|}{ Recovered } & \multicolumn{2}{|c|}{$\begin{array}{c}\text { Discharge } \\
\text { against } \\
\text { medical } \\
\text { advice }\end{array}$} & \multicolumn{2}{|c|}{ Death } & \multicolumn{2}{|c|}{$\begin{array}{c}\text { Permanent } \\
\text { infirmity } \\
\text { (Bone Loss) }\end{array}$} & \multicolumn{2}{|c|}{ Total } & & \\
\hline & $\mathrm{No}$ & $\%$ & $\mathrm{No}$ & $\%$ & $\mathrm{No}$ & $\%$ & $\mathrm{No}$ & $\%$ & $\mathrm{No}$ & $\%$ & & \\
\hline $\begin{array}{c}\text { Brain } \\
\text { contusion }\end{array}$ & 27 & 7.1 & 1 & 4.5 & 0 & .0 & 0 & .0 & 28 & 6.6 & & \\
\hline Fracture & 112 & 29.6 & 13 & 59.1 & 5 & 29.4 & 4 & 80.0 & 134 & 31.7 & & \\
\hline Hemorrhage & 98 & 25.9 & 4 & 18.2 & 5 & 29.4 & 1 & 20.0 & 108 & 25.5 & & \\
\hline $\begin{array}{c}\text { Mixed } \\
\text { (fracture, brain } \\
\text { contusion, } \\
\text { hemorrhage) }\end{array}$ & 77 & 20.3 & 2 & 9.1 & 7 & 41.2 & 0 & .0 & 86 & 20.3 & 22.405 & 0.033 \\
\hline $\begin{array}{c}\text { Free } \\
\text { (No lesion) } \\
\end{array}$ & 65 & 17.2 & 2 & 9.1 & 0 & .0 & 0 & .0 & 67 & 15.8 & & \\
\hline Total & 379 & 100 & 22 & 100 & 17 & 100 & 5 & 100 & 423 & 100 & & \\
\hline
\end{tabular}

$* \mathrm{P}<0.05$ is significant $(\mathrm{S})$. 


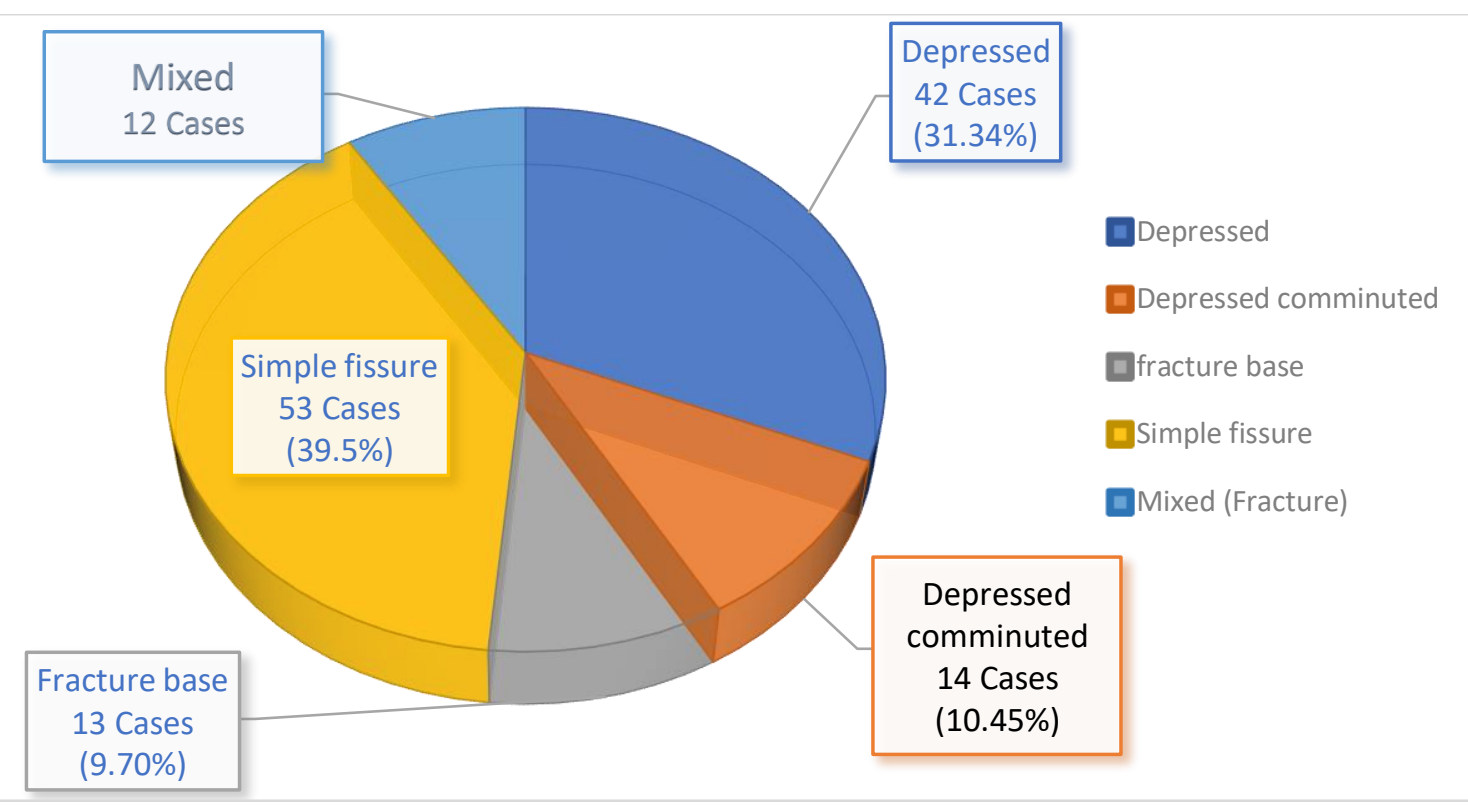

Figure (1): Distribution of cases according to type of skull fracture among fractured cases.

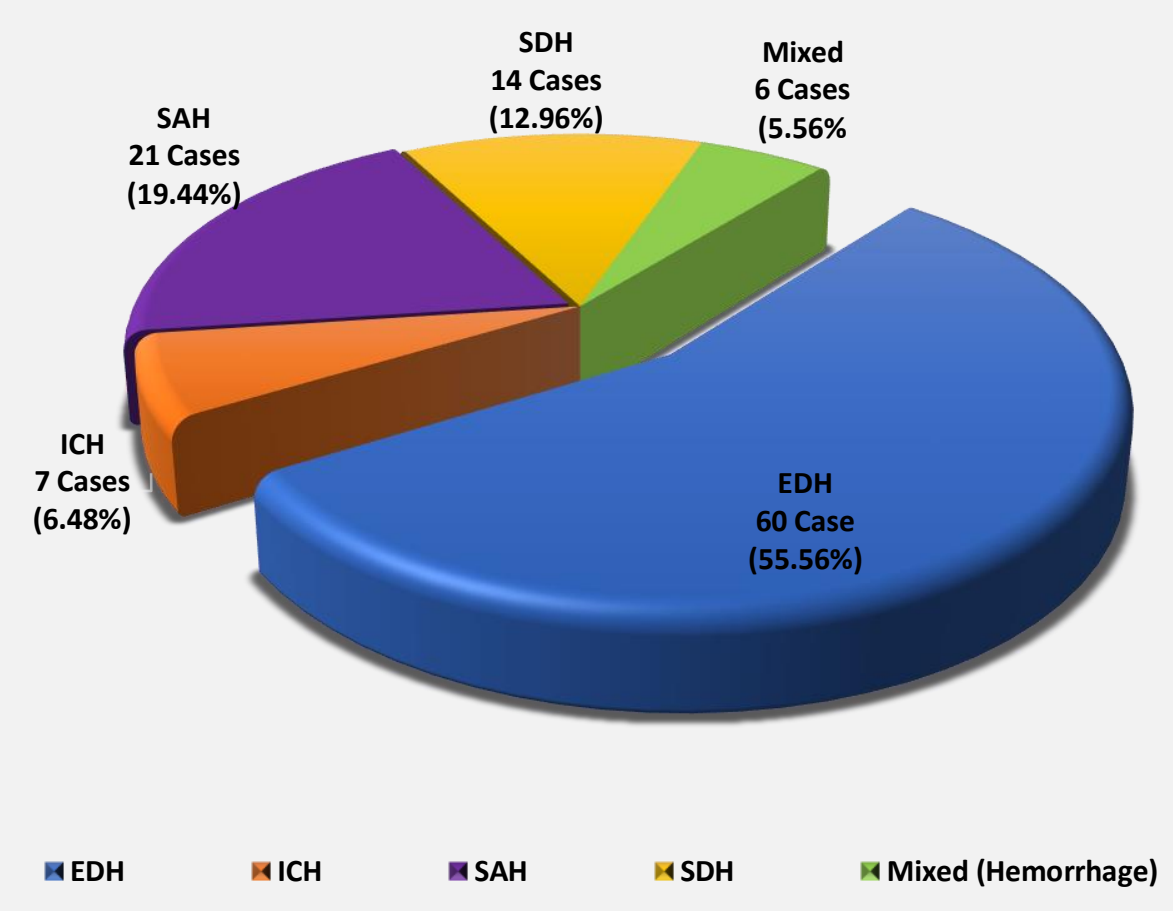

Figure (2): Distribution of cases according to type of intracranial haemorrhage among haemorrhagic cases. $(\mathrm{EDH})=$ epidural hemorrhage, $(\mathrm{SDH})=$ subdural hemorrhage, $(\mathrm{SAH})$ $=$ subarachnoid hemorrhage, $(\mathrm{ICH})=$ intra cerebellar hemorrhage. 


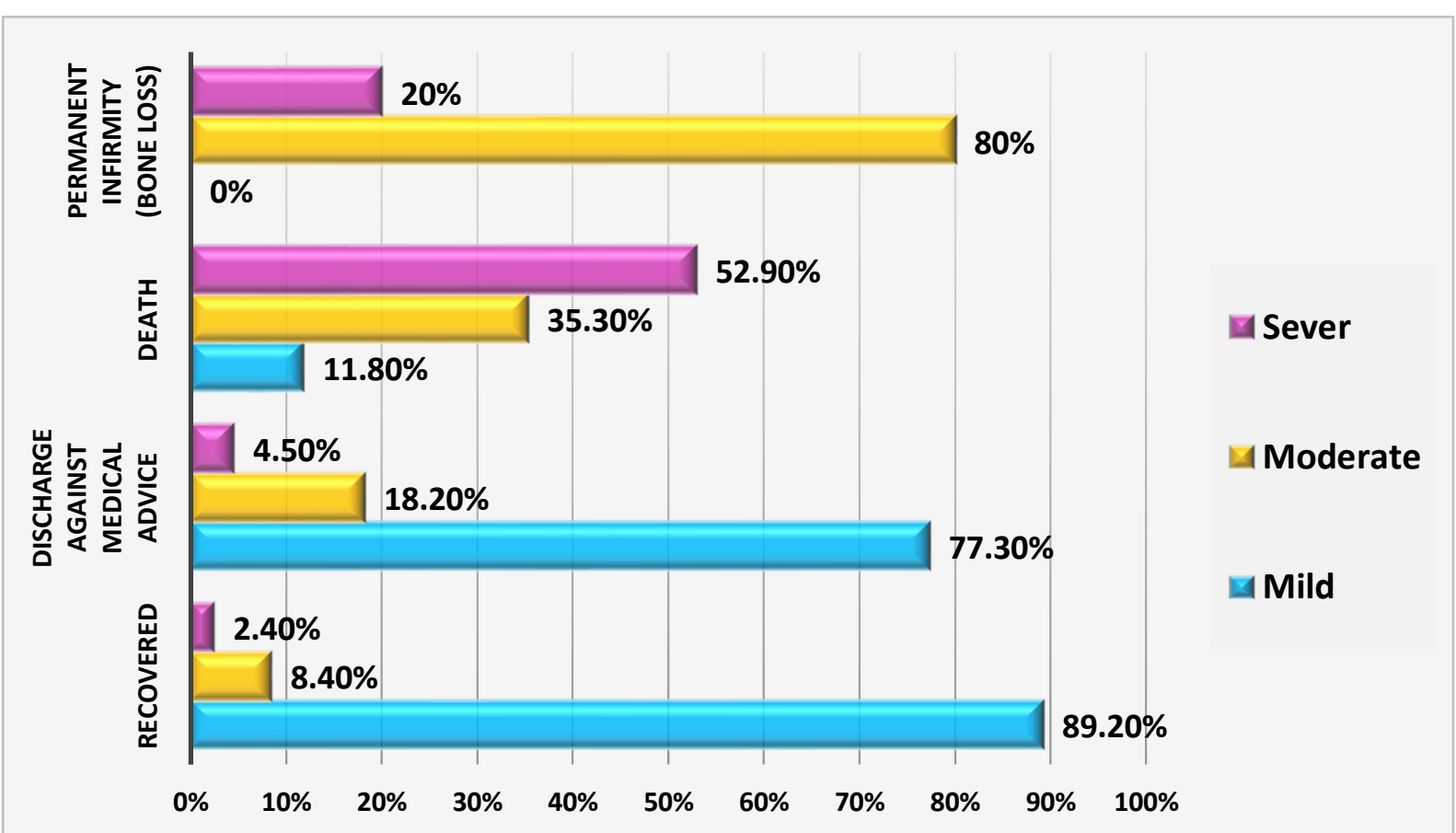

Figure (3): Chi square statistical analysis of the relation between the outcome and GCS ( $\mathrm{X}^{2}$ $=140.9$ and $* * \mathrm{P}$ value $<0.001$ is highly significant $(\mathrm{HS})$.

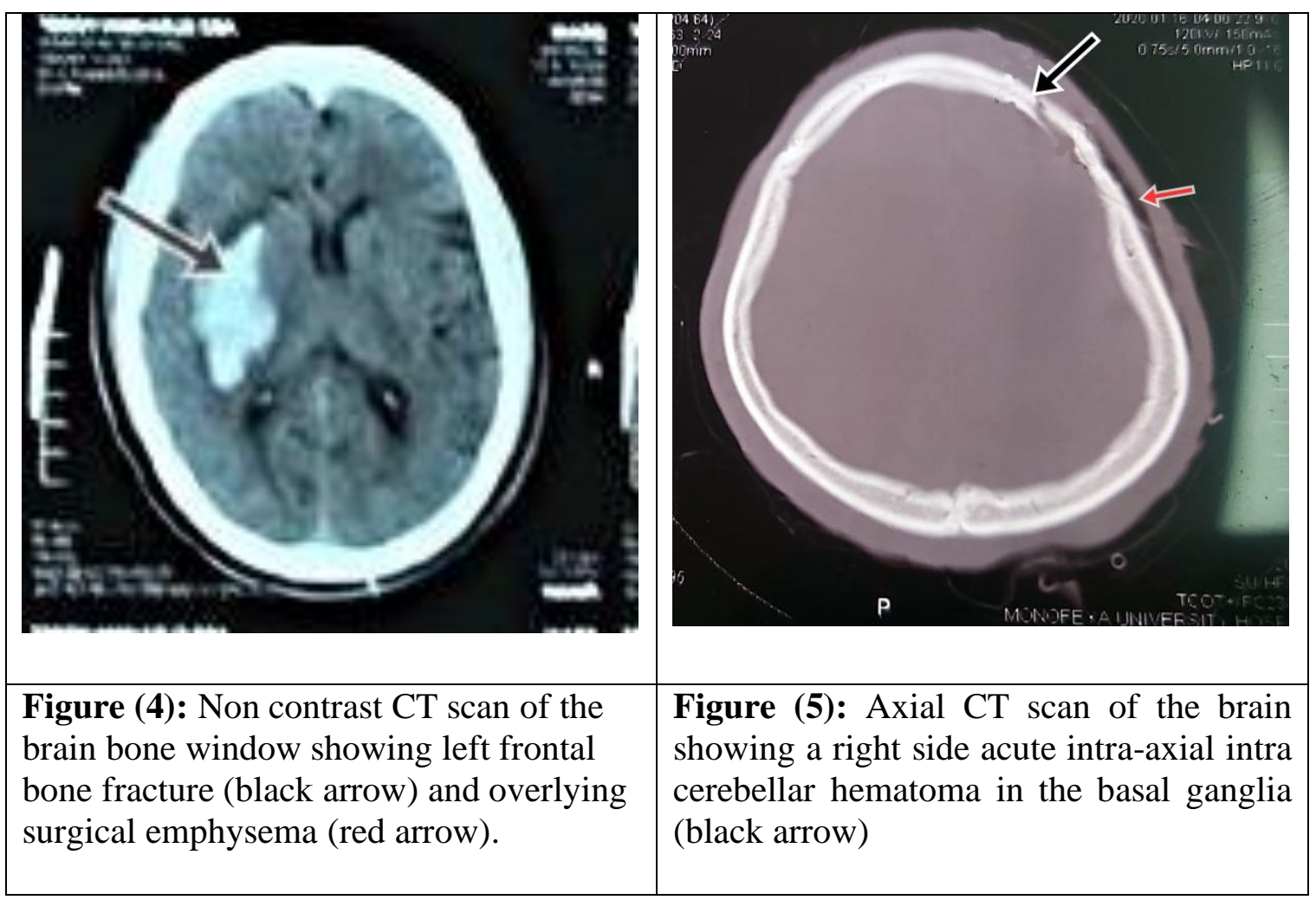




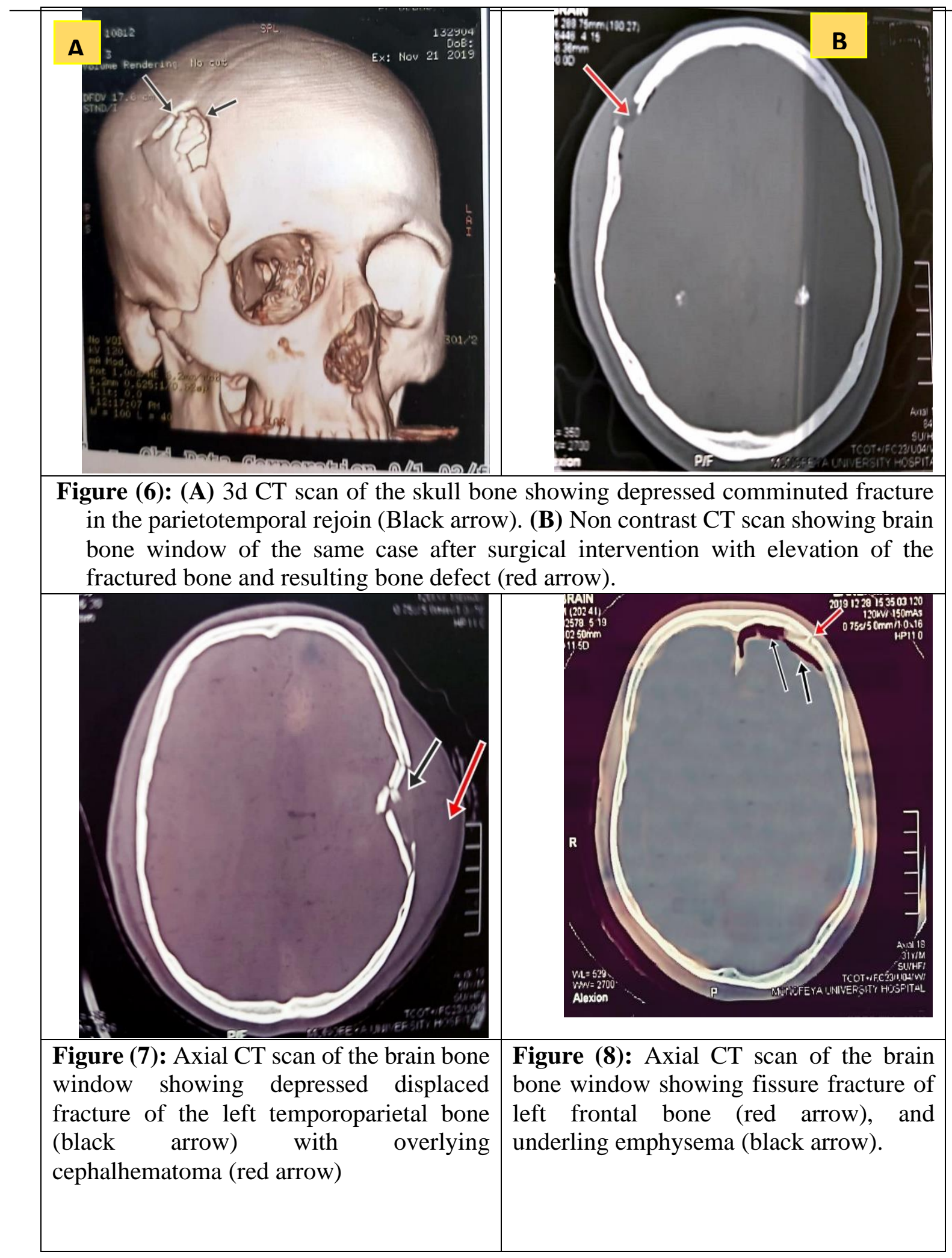




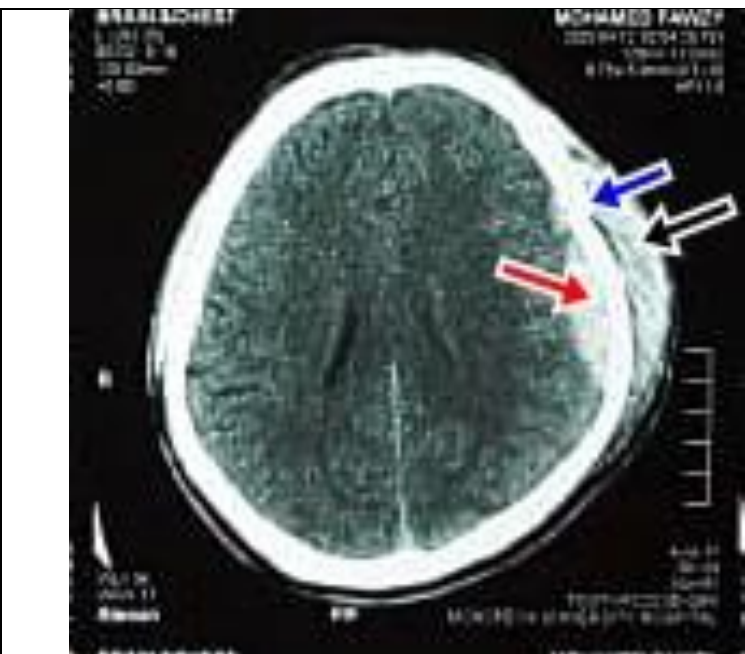

Figure (9): Axial CT scan of the brain showing fractured left frontal bone (blue arrow), with underling left frontoparietal acute epidural hematoma (red arrow) and overlying cephalhematoma (black arrow).

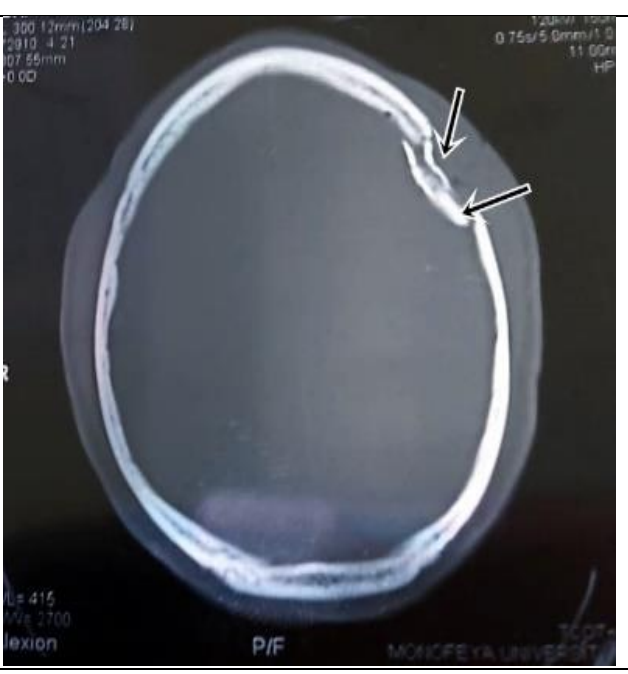

Figure (10): Axial CT scan of the brain bone window showing depressed fracture of left frontal bone (black arrow).

\section{DISCUSSION}

Head injury increases with considerable morbidity and mortality from day to day. Its knowledge for preventive and curative management is crucial especially in our country as about 12,000 Egyptians died each year from various forms of trauma (El Shehaby et al., 2020).

In this study about 423 cases of traumatic head injury admitted during the period of the study to Menoufia University Hospital, which is a main hospital that provides medical services to the main cities and villages in the surrounding.

As regards the age of cases, more than half of THI cases $(56 \%)$ were between 15 and 45 years, whereas the lowest number were more than 60 years by $5 \%$ of all cases, this was in accordance with (Sivakumar et al., 2018) in India and various studies conducted in South Africa, England and Belgium found that young people in active age groups were the highest age to sustain head injury (Maas et al., 2008; Jasper et al., 2014). The result of this study might be because young adults are the family's prime bread earners and stay outside most of the day. In addition, by nature youths engage in more violent actions while individuals in extreme of ages usually stay indoors longer so their number may be smaller than other age groups (Perron and Howard, 2008). In contrast to (Refaat et al., 2019) in their study where children were the most commonly affected age group.

Males in this study were approximately three times more likely than females to have HI, similar findings were found in other studies as Taha and Barakat, (2016) in Egypt and Hassan et al., (2017) in Pakistan and agreed with Walle et al., (2018) in Ethiopia. As males always work outdoors and therefore more often prone to road accidents ,assaults, and injuries, also men are more likely faced with stressful situations, making them more vulnerable to being entangled in acts of violence (EI Farouny and Habib, 2019). This reflect the vulnerability of that age group and gender for trauma and the bad impact on their productivity life (Hemalatha and Singh, 2013).

The incidence of head injuries among cases from rural areas (59.6\%) outnumbered that from urban areas $(40.4 \%)$. This agreed with (Eshete and Taye, 2018) in Southern Ethiopia. This can be referred to the rural nature of Menoufia 
governorate. Rural areas are not only distinct from urban areas in terms of location and socioeconomic background, but also in terms of the complexity of the dynamics of work and the environmental conditions encountered in rural areas. Rural areas typically had more jobs that expose people to traumatic hazards. Also, transportation challenges across bad constructed roads and long distances to their workplaces or vital areas in the governorate making them more susceptible to accidents and injuries (Robertson and McConnel, 2011).

As regard the occupation daily laborers constituted the highest percent $(27.19 \%)$ of the affected cases this may be because they try to find more than one work which may have high risk of injury because of their low-income level, plus they don't care about using personal protective equipment at work; that making them highly exposing to fall or accidents. This is consistent with other reports from Aenderl et al., (2014); Wui et al., (2014) and McMillan et al., (2015).

Among head injury cases, the most common cause was RTA in $(48.7 \%)$ followed by assault in (40.2\%) while the least prevalent incidence was fall related injuries. Similar findings were found in studies conducted by (Chen and Howng, 1995) stated that $70 \%$ of cases were due to road traffic accident, and still nowadays on the same way with, Pate et al., (2017) survey in India, Chelly et al., (2019) in Malaysia and Refaat et al., (2019) in Egypt who reported that RTA was the most prevalent cause of head injuries. That high occurrence rate of serious head injuries caused by RTA may refer to the fast and intense traffic movement as well as growing demand in heavily populated areas, increasing number of vehicles, ignoring traffic laws and speed restrictions, incompetent traffic network, poorly planned and congested roads, absence of awareness of wearing protective helmets plus the behavior of the new generation with high-speed vehicles are all blamed for increasing road traffic accidents (Majdan et al., 2013; Pate et al., 2017). Unlike Pope, (2012) who confirmed that falling injuries (31.5 percent) were by far the most frequent cause of head injury in the U.S., followed by road accidents and lastly assaults. At the other hand, a survey from Australia found that the bulk of injuries were caused by sporting and recreation incidents (Amaranath et al., 2014), this variation may be due to cultural differences among the studded participants (Walle et al., 2018).

Also highly statistically significant relation was found between different causes of traumatic head injury in relation to the age groups where RTA was more common among age group (45- <60 y) by $(27.4 \%)$ In comparison, other studies carried out by Maegele et al. (2019) in Germany found similar result where the highest rate of head injuries due to motor vehicle accidents were between the ages of $44 \mathrm{y}$ and $60 \mathrm{y}$ and this may be attributed to work-related accidents which are normal in this age group, beside that most of drivers are in that age group whom may be suffering from chronic health disease affecting the concentration and visual field, while fall was more common in age group less than $15 \mathrm{y}$ by (34\%) and that is logic in young age group as they play and move accidentally without measuring their steps. On the other hand, assault injuries were more common in age group (30-<45y) by $(39.8 \%)$ as that age well known by entangling in violent behavior and acts.

Blunt instrument in this study was the most frequent blamed instrument in $(91 \%)$ versus $(6.6 \%)$ caused by sharp instrument. These findings were in line with the results of Mohanty et al., (2005) in India, Agrawal et al., (2016); Eshete and Taye (2018) in Athiopia and Refaat et al., (2019) in Egypt, who found blunt trauma to be the most common agent, while the least common was firearm trauma. This possibly because most of cases were due to RTA where blunt agents are common due to vehicle collision. Blunt instruments are widely used as they are cheap, readily 
accessible they are mostly household instruments (Mohanty et al., 2005). Also, the attackers think that blunt trauma to head and penetrating trauma to chest and abdominal is always deadly. Blunt head injury rates are very high worldwide, particularly in the more densely populated countries with heavy and quick traffic flows (Azher et al., 2017).

As regards the most liable site for head injury, the present results declared that multiple areas of the vault of skull were the most frequent sites, present in $30.3 \%$ and the least affected site was the basal bone $2.6 \%$. These results were parallel to results of Hardman, (2002) in North America and Chattopadhyay and Tripathi (2010) in India found that in $69.3 \%$ of cases multiple cranial bones were affected. These findings could be explained by that head areas are targets for multiple violence attacks moreover vault areas are more exposed than skull base, so fracture vault is more common than basal fracture. However, a study done by Consunji et al., (2013) in the Philippines, reported that maxillofacial injuries were the most frequent among young adult males.

Injury to the scalp is very common in traumatic head injuries. Type of scalp injury is important to establish the causative tools of injury and analyze its mechanisms. Any scalp injury should be considered serious regardless of the case presentation (Azher et al., 2017). In this study almost all cases were complaining of different types of scalp injury; where $(49.9 \%)$ complained mixed injuries in the form of (contusion, contused wound, and/ or cut wound), (26\%) had abraded contusion and (19.4\%) of cases had contused wound versus $4.7 \%$ of cases had cut wound. According to Aghakhani et al., (2014) scalp injuries were found in 76.2 percent of people with traffic accident and 75 percent among fall injuries. This can be explained by the strong blunt force, loose areolar space available for blood deposition under the scalp, limited scalp musculature and the velocity of collision or fall to the ground all of that make scalp affection is very common and in multiple forms (Kumar et al., 2014).

The severity of cases in this study was based on the GCS where most cases sustained mild score 357 (84.4\%), 46 $(10.9 \%)$ sustained a moderate score, while $20(4.7 \%)$ sustained severe score. This agrees with other previous studies (Yates et al., 2006; Qureshi et al., 2013; Eshete and Taye (2018) and Refaat et al., 2019). However Senthilkumar et al., (2017) found a slightly greater occurrence of moderate score GCS in head injury; that might be due to the concentration on maxillofacial trauma in his study.

Complete recovery was the most prevalent outcome representing $(89.6 \%)$ versus $(4 \%)$ deaths and $(1.2 \%)$ permanent infirmity this was coincident with Refaat et al., (2019) in Egypt and Umeranı et al., (2014) in Pakistan as they noticed that complete recovery was the commonest finding. The high prevalence of complete recovery in this study might be due to the presence of specialized neurosurgical unite in our university hospital, increased intracranial imaging with CT scanning for early diagnosis and management, and the progress in care of acute patient trauma are likely to lead to these patterns.

Imaging plays a key role in treating THI patients; according to CT finding skull fracture was the most common finding (31.7\%) among all cases followed by intracranial hemorrhage $(25.5 \%)$ then mixed finding in $(20.3 \%)$, free finding constituted $(15.8 \% \%)$ as they were with no apparent lesion in CT or not indicated for doing it, while the least common were only brain contusion $(6.6 \%)$. CT is the technique of choice for imaging acute head trauma, allowing effective diagnosis and care, according to Lolli, et al., (2016). The commonest type among the fractured cases was simple fissure fracture $(39.5 \%)$ followed by depressed fracture (31.3\%), this coincides with Thube et al., (2015); Azher et al., (2017) and Pate et al., (2017) who found that simple fissure fracture was the predominant $(50 \%)$ in his study. 
However, by looking on the distribution of patients according to type of hemorrhage in CT, the most prevalent type was epidural hemorrhage $(\mathrm{EDH})$ in (55.5\%), followed by subarachnoid hemorrhage (SAH) in (19.4\%), subdural hemorrhage (SDH) in (12.9\%) and lastly intracerebral $(\mathrm{ICH})$ and mixed types of hemorrhage in $6.4 \%$ and $5.5 \%$ respectively ; these results were in agreement with Refaat et al., (2019) who declared that the elevated incidence of epidural hemorrhage $(\mathrm{EDH})$ is attributable to the fact that in most cases there was blunt force impact over skull bony regions which eventually contributes to breaking of the blood vessels in the epidural area. this contrasted with Pate et al., (2017) where subarachnoid hemorrhage was the commonest finding and Maas et al. (2008) who stated that highest incidence in his study was subdural hemorrhage. Such conflicting findings may be attributed to the different forms of injuries that cause other forms of hemorrhage to be prominent in traumatic head injuries than epidural (Alnaami et al., 2019).

There was highly significant relation between GCS of cases and their outcome, as $89.2 \%$ of recovered cases were mild versus $52.9 \%$ of dead cases were sever; this gives strong prove that GCS can be considered a good predictor for the prognosis of traumatic cases (Lynch, 2013). Eshete and Taye, (2018) reported that patients who died as a result of head injury were associated with lower GCS and were more likely to experience increased risk of infection and complication relative to patients with mild or moderate score.

In this study significant relation between the radiological finding in $\mathrm{CT}$ and the outcome of cases, as the highest percent of recovered cases $(29.6 \%)$ had only simple fissure fracture, while $41.2 \%$ of dead cases had mixed radiological finding (fracture, brain contusion, hemorrhage) which affect the severity of cases and indicate poor outcome. On the other side $80 \%$ of cases with Permanent infirmity in form of (Bone
Loss) had skull fracture after surgical management. which indicate the crucial role of CT in early diagnosis and appropriate management. Recent studies suggested that it also helps in predicting patient outcomes (Lolli, et al., 2016).

\section{CONCLUSION}

Traumatic injury to the head is a common injury presented to the Menoufia University Hospital emergency unite. The total number of THI cases was 423 . The age group most affected was between (30$<45 \mathrm{y})$.

Most cases were males. Rural cases outnumbered those from urban areas. The most affected categories were laborer and student. RTA was the most common cause of traumatic head followed by assault and blunt agents were the most blamed instrument.

The mostly affected bone of skull was the multiple sites. skull fracture was the most common finding in CT followed by intracranial hemorrhage. GCS and CT finding are very important in prediction of traumatic cases outcome as they are associated significantly with their outcome at time of discharge.

\section{RECOMMENDATION}

Head injury is public health threat that is recognized as causing death and impairment. It reflects a deplorable financial burden on developing countries such as Egypt.

Since most traumatic head injuries are preventable, the design of injury prevention strategies includes detailed and accurate information on injuries to focus on programs and resources are needed in Egypt.

The goal must be to decrease head injuries, and this can be done by raising socioeconomic conditions, educational standards and applying more security measures to this evolving lifestyle.

Preventive approaches are the best way to cut trauma sequelae's cost. It is necessary from Government authority to be 
concerned with taking appropriate and immediate measures to reduce its incidence. Simultaneously, people should be advised to take appropriate protective steps to avoid head injury. Head injuries resulting from motor vehicle collisions can be minimized by wearing seat belts, driving vehicles with air bags and avoiding violent driving behaviors. Helmets that are regularly used can reduce head injury when riding a motorcycle or a bicycle.

This is equally significant in terms of improving road safety and implementing tougher regulations.

first aid facilities, ambulance services and qualified health personnel should be provided along highways and main roads for rapid assessment and transportation of the injured people to nearest hospitals.

The provision of contingency resources such as specialized intensive care units and trauma team in every central hospital helps in early proper management.

Educational campaigns on RTAs and sequelae of interpersonal violence can decrease the admission of patients with head injury.

\section{REFERENCES}

Abdelgeleel, N. M., Salama, K. M., Ali, M. A., and Elsagher, A. N. (2019): Assessment of management of polytrauma patients in the emergency department in Suez Canal University hospital. International Surgery Journal, 6(6), 1844-1850.

Aenderl, I., Gashaw, T., Siebeck, M., and Mutschler, W. (2014): Head injury-a neglected public health problem: a four-month prospective study at Jimma University specialized hospital, Ethiopia. Ethiopian journal of health sciences, 24(1), 27-34.

Aghakhani, K., Heidari, M., Yousefinejad, V., and Okazi, A. (2014): Frequency of intracranial injury in cadavers with head trauma with and without scalp injury in Tehran. Journal of forensic and legal medicine, 28, 36-38.
Agrawal, D., Ahmed, S., Khan, S., Gupta, D., Sinha, S., and Satyarthee, G. (2016): Outcome in 2068 patients of head injury: Experience at a level 1 trauma centre in India. Asian journal of neurosurgery, 11(2), 143-5.

Alnaami, I., Alshehri, S., Alghamdi, S., Ogran, M., Qasem, A., Medawi, A.,et al., (2019): Patterns, types, and outcomes of head injury in Aseer Region, Kingdom of Saudi Arabia. Neurosci J, 2019, e2782146-e2782146.

Amaranath J. E., Ramanan M., Reagh, J., Saekang E., Prasad, N., Chaseling, R., et al., (2014): "Epidemiology of traumatic head injury from a major pae- diatric trauma centre in New South Wales, Australia". ANZ Journal of Surgery, 84(6), 424428.

Azher, T., Ansari, A. J., and Ahmad, Z. (2017): Study of skull fracture pattern in cases with head injury by blunt force. JM HS, 11(1), 486-8.

Chattopadhyay, S., and Tripathi, C. (2010): "Skull fracture and haemorrhage pattern among fatal and nonfatal head injury assault victims-a critical analysis". Journal of injury and violence Research, 2(2), 99.

Chelly, H., Bahloul, M., Ammar, R., Dhouib, A., Mahfoudh, K. B., Boudawara, et al., (2019): Clinical characteristics and prognosis of traumatic head injury following road traffic accidents admitted in ICU "analysis of 694 cases. European journal of trauma and emergency surgery, 45(2), 245-253.

Chen, C. L., and Howng, S. L. (1995): The incidence and mortality rates of head injuries in Kaohsiung City, Taiwan (1991-1992). Gaoxiong yi xue ke xue za zhi= The Kaohsiung journal of medical sciences, 11(9), 537-545.

Consunji, R. J., Larona, A. J. L., Jumangit III, A. C., and Ameratunga, S. N. (2013): Motorcycle-related trauma in the Philippines resulting in hospital 
admission: the epidemiology of cases at the Philippine General Hospital. Acta Medica Philippina, 47(3).

Dawson, B., and Trapp, R. G. (2004): Basic and clinical biostatistics. Singapore, 2001, 141-142.

El Shehaby, D. M., Farahat, A. M. A., Shahine, M. S., and Mohammed, $\mathbf{H}$. M. (2020): Medico-legal evaluation and trend of the different patterns of maxillofacial fractures concomitant with closed head injury in Upper Egypt: retrospective study. Egyptian Journal of Forensic Sciences, 10 (1), 19.

El-Farouny, R. H. and Habib, N. (2019): Evaluation of Relation Between Interpersonal Violence and Drug Abuse on Cases Attended to Menoufia University Hospital (A Prospective Study). The Egyptian Journal of Forensic Sciences and Applied Toxicology, 19(1), 17-37.

Eshete, A., and Taye, F. (2018): Magnitude of severe head injury and its associated factors among head injury patients in Gedeo zone, southern Ethiopia: a two-year retrospective study. Ethiopian journal of health sciences, 28(3), 323-330.

Hardman, J. M., and Manoukian, A. (2002): Pathology of head trauma". Neuroimaging Clinics of North America, 12(2), 175-87.

Hassan, N.; Ali, M.; Haq, N.U.; Azam, F.; Khan, S.; Khan, Z. et al., (2017): Etiology, clinical presentation and outcome of traumatic brain injury patients presenting to a teaching hospital of Khyber Pakhtunkhwa. Journal of Postgraduate, 31(4): 365-70.

Hemalatha, N., and Singh, O. G. (2013): Patterns of Cranio-intracranial injuries In Fatal Head Injury Cases. Journal of Indian Academy of Forensic Medicine, 35(2), 106-108.

Jasper, U. S., Opara, M. C., Pyiki, E. B. and Akinrolie, O. (2014): The Epidemiology of Hospital-referred Head Injury in Northern Nigeria.
Journal of Scientific Research and Reports, 3(15), pp. 2055-2064.

Kumar, L., Agarwal, S., Singh, T., and Garg, R. (2014): Patterns of head injury at tertiary care hospital. International Journal of Scientific Study, 1(5), 5-8.

Pope, T. L. (2012). Harris \& Harris' The Radiology of Emergency Medicine. Lippincott Williams \& Wilkins.

Lolli, V., Pezzullo, M., Delpierre, I. and Sadeghi, N. (2016): MDCT imaging of traumatic brain injury. The British journal of radiology, 89(1061), 20150849.https://doi.org/10.1259/bjr.2 0150849

Lynch, C. (2013): The Epidemiology and Predictors of Worse Outcome for Traumatic Brain Injury Patients at Kilimanjaro Christian Medical Center, Moshi Tanzania (Doctoral dissertation, Duke Global Health Institute;1-35.

Maas, A. I., Stocchetti, N., and Bullock, R. (2008): Moderate and severe traumatic brain injury in adults. The Lancet Neurology, 7(8), 728-741.

Maegele, M., Lefering, R., Sakowitz, O., Kopp, M. A., Schwab, J. M., Steudel, W. I.et al., (2019): The Incidence and Management of Moderate to Severe Head Injury: A Retrospective Analysis of Data From the Trauma Register of the German Trauma Society. Deutsches Ärzteblatt International, 116(10), 167.

Mahran, D. G., Farouk, O. A., Qayed, M. H., and Berraud, A. F. (2013): Hospitalized injuries and deaths in a trauma unit in upper Egypt. International journal of critical illness and injury science, 3(4), 235.

Mahran, D. G., Farouk, O., Qayed, M. H., and Berraud, A. (2016): Pattern and trend of injuries among trauma unit attendants in Upper Egypt. Trauma monthly, 21(2).

Majdan, M., Mauritz, W., Wilbacher, I., Janciak, I., Brazinova, A., Rusnak, M., et al., (2013): Traumatic brain injuries caused by traffic accidents in 
five European countries: outcome and public health consequences. The European Journal of Public Health, 23(4), 682-687.

McMillan, T. M., Laurie, M., Oddy, M., Menzies, M., Stewart, E., and Wainman-Lefley， J.(2015): "Head injury and mortality in the homeless". Journal of Neurotrauma, 32(2),116119.

Meaney, D. F., and Smith, D. H. (2011): Biomechanics of concussion. Clinics in sports medicine, 30(1), 19-31.

Mohanty, S., Mohanty, M. K., Panigrahi, M. K., and Kumar, S. (2005): Fatal head injury in homicidal victims. Medicine, science and the law, 45(3), 244-248.

Mostafa, H. E. S., Abouhashem, N. S., and Hussein, M. H. S. (2016): Timing of Traumatic Brain Injury And Its Systemic Effects On The Lungs Of Adult Male Albino Rats. The Egyptian Journal of Forensic Sciences and Applied Toxicology, 16(2), 169-191.

Pate, R. S.; Hire, R. C. and Rojekar, M. V. (2017): Pattern of head injury in central India population. International Journal of Research in Medical Sciences, 5:(8):3515-3519

Pearn, M.L.; Niesman, I.R.; Egawa, J. Sawada, A.; Almenar-Queralt A.; Shah, S. B.et al., (2017): Pathophysiology Associated with traumatic brain injuries in North Texas children. Rural and remote health, 11(1), 1521-1521.

Rupani R, Verma A and Rathore $\mathbf{S}$ (2013): Pattern of Skull Fractures in Cases of Head Injury. J Indian Acad Forensic Med ;35(4):971- 973.

Salottolo K, Levy AS, Slone DS and Mains CW. (2014): The Effect of Age on Glasgow Coma Scale Score in Patients with Traumatic Brain Injury. JAMA Surg.; 149 (7):727-734.

Senthilkumar, R., Priya, A. K., and Anandan, H. (2017): Analysis of the Outcome of Mandible Fracture
Traumatic Brain Injury: Current Treatments and Potential Novel Therapeutics. Cellular and Molecular Neurobiology, 37(4):571-585

Perron, B. E., and Howard, M. O. (2008): "Prevalence and correlates of traumatic brain injury among delinquent youths". Criminal behaviour and mental health: CBMH, 18(4), 243.

Qureshi, J. S., Ohm, R., Rajala, H., Mabedi, C., Sadr-Azodi, O., AndrénSandberg, A., et al., (2013): Head injury triage in a sub Saharan African urban population. International Journal of Surgery, 11(3), 265-269.

Ranjit M., Tandle A. N. and Keoliya (2011): Patterns of Head Injuries in fatal road traffic accidents in a rural district of Maharashtra-Autopsy based study: JIAFM J., Vol.33 (3).

Refaat, R. M., Haroun, M. R., El Din, S., and Hussein, A. Y. (2019): Medico Legal Aspects of Traumatic Head Injuries in Benha University Hospital (Prospective Analytical Study). The Egyptian Journal of Forensic Sciences and Applied Toxicology, 19(4), 119145.

Robertson, B., and McConnel, C. (2011): Town-level comparisons may be an effective alternative in comparing rural and urban differences: a look at accidental

Management. International Journal Of Scientific Study, 5(3), 179-184.

Sivakumar, R., Subrahmanyam, B. V., Phanindra, S. V., Munivenkatappa, A., Kumar, S. S., and Agrawal, A. (2018): A descriptive study of craniocerebral injuries admitted in tertiary care center of coastal Andhra Pradesh. Romanian Neurosurgery, 32(2),384390.

Taha MM and Barakat MI (2016): Demographic Characteristics of Traumatic Brain Injury in Egypt: Hospital Based Study of 2124 Patients. J Spine Neurosurg 5:6. 
Thube, H. R., Pawale, D. A., and Jagtap, N. S. (2015): Study of Pattern of fatal experience from a tertiary care center in Pakistan. Turkish neurosurgery, 24(1), 19-24.

Walle, T. A., Tiruneh, B. T., and Bashah, D. T. (2018): Prevalence of head injury and associated factors among trauma patients visiting surgical emergency department of Gondar University Referral Hospital, Northwest Ethiopia 2016. Across-sectional study. International journal of Africa nursing sciences, 9, 57-61.

Wang, J.; Han, F.; Zhao, Q.; Xia, B.; Jialin Dai, J.; Wang, Q. et al. (2018): Clinicopathological characteristics of traumatic head injury in juvenile, Middle-Aged and Elderly Individuals. international medical journal of experimental and clinical research, 24: 3256-3264.

Wui, L. W., Shaun, G. E., Ramalingam, G., and Wai, K. M. (2014): Epidemiology of trauma in an acute care hospital in Singapore. Journal of emergencies, trauma, and shock, 7(3), 174.

Yates, P. J., Williams, W. H., Harris, A., Round, A., and Jenkins, R. (2006): An epidemiological study of head injuries in a UK population attending an emergency department. Journal of Neurology, Neurosurgery and Psychiatry, 77(5), 699-701.

Umerani, M. S., Abbas, A., and Sharif, S. (2014): Traumatic brain injuries: head injury in Kolhapur region. J Forensic Med Sci Law, 24(2), 11-5. 


$$
\begin{aligned}
& \text { تقيّم نمط ونتائج إصابات الرأس في مستشفى العربى جامعه المنوفية على مدى عام } \\
& \text { ريهام حسن الفرعونى الإيكي } \\
& \text { قسم الطب الثرعي والسموم الإكلينيكية ـ كليه الطب ـ جامعه المنوفية }
\end{aligned}
$$

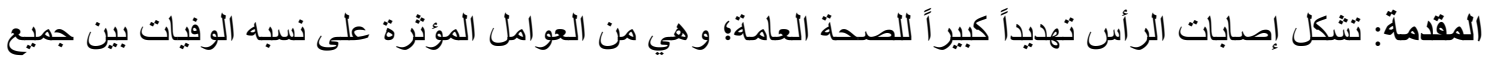

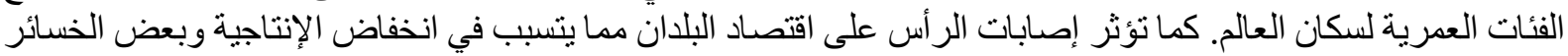

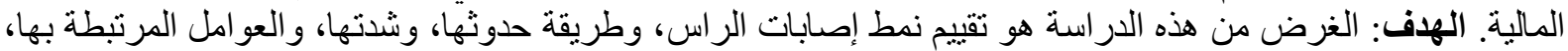

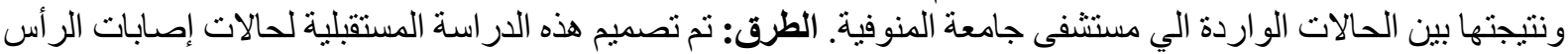

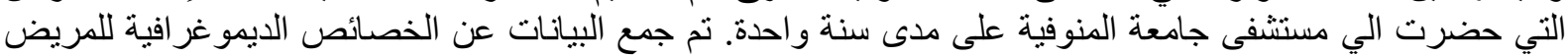

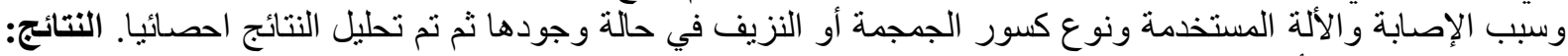

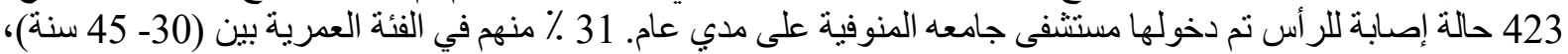

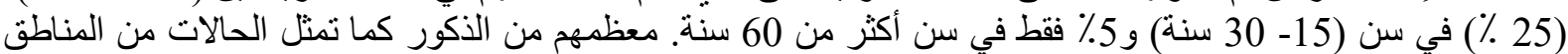

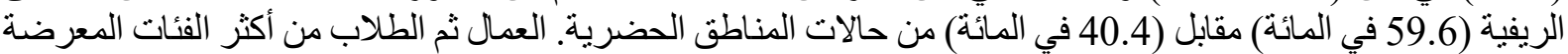

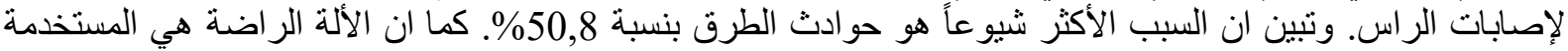

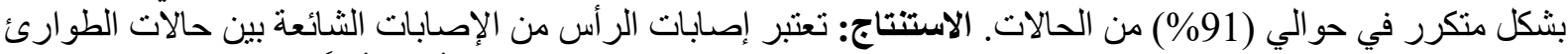

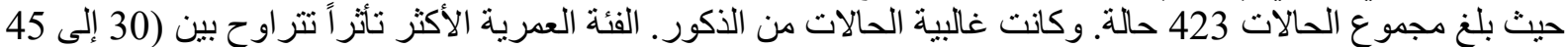

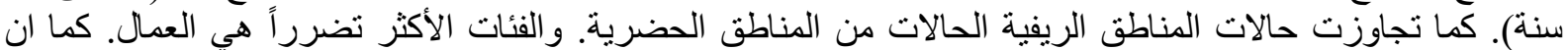

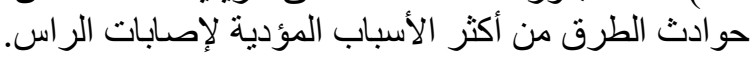

